\title{
TRANSIENT VOLTAGE DISTRIBUTION IN TRANSFORMER WINDING
}

\section{(EXPERIMENTAL INVESTIGATION)}

\author{
Kanchan Rani ${ }^{1}$, R. S. Gorayan ${ }^{2}$ \\ ${ }^{1}$ M.tech Student, ${ }^{2}$ Professor, Electrical Department IIT (BHU), VARANASI, U.P India, \\ kanchan.rani.eee11@itbhu.ac.in,rsgorayan.eee@iitbhu.ac.
}

\begin{abstract}
In this work, the non-liner voltage distribution in transformer winding is investigated that occurs due switching and lightning. Transformer winding is modeled in the alternative transients program (ATP) version of Electromagnetic transients program (EMTP$R V)$. EMTP software is used to simulate the very fast transient overvoltage. An experimental setup that consist of, Recurrent surge generator, CRO and transformer winding model has been developed and voltages measured at different point along the transformer winding. Simulation results show good agreement with the experimental result.
\end{abstract}

Index Terms: Very fast transient overvoltages, internal resonance, impulse voltage distribution, disc winding

\section{INTRODUCTION}

It is well known that switching operation in the Gas insulated switchgears (GIS) produces very fast transient over voltages (VFTO). VFTO have very short rise time of .1 $1 \mu \mathrm{sec}$ or less and its main oscillating frequency range is in between $1 \mathrm{MHz}$ to $50 \mathrm{MHz}[1]$.

The distribution of these transient over voltages in transformer winding is highly non uniform. It has been observed that 60 Percent of these voltages appears across first 10 percent length of the winding. This non uniform voltage distribution can damage the transformer insulation [2].

This work deals with the voltage distribution in the transformer winding when its terminal is excited with impulse voltage. Study is aimed to analyze the nature of the internal voltage amplification and voltage stress at various points of transformer winding with impulse excitation. A transformer winding model is developed on the EMTP software. Simulation results are compared with the experimental results and a satisfactory result are obtained.

\section{TRANSFORMER WINDING MODEL}

For the study of the transients response of the transformer a high frequency circuit model of $100 \mathrm{KVA}$ transformer model has been developed based on geometry and configuration. While calculating phenomena associated with such high frequencies, the capacitance of transformer winding is important, although it is of no importance at power frequency voltage levels. The most detailed model of the transformer is one in which every turn of the winding is represented and all capacitances and inductances are included. Such a model may be prohibitive in terms of memory and complexity. The details can be reduced, by taking some assumption, to simplify L, C, network without losing much accuracy. A schematic diagram of the developed model is shown as in Figure1

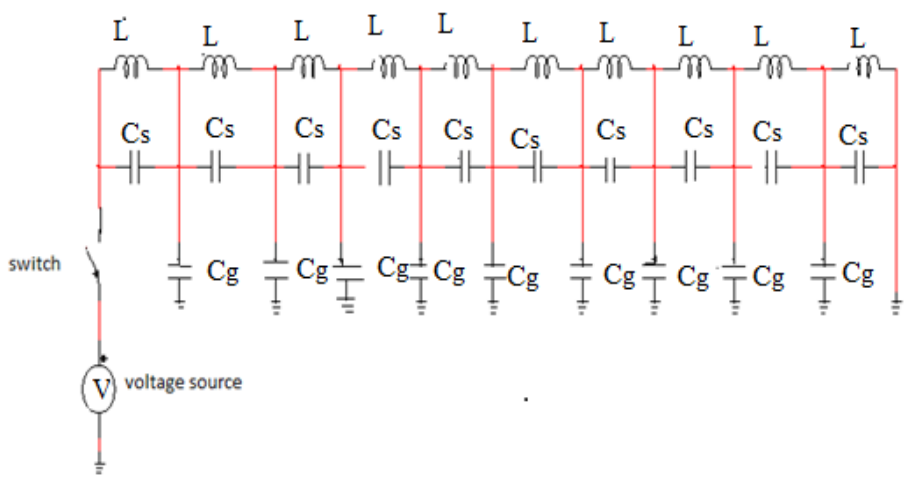

Fig. 1: Simplified Equivalent model for Transformer Winding

It is assumed that the winding is uniform i.e. all the series capacitance are equal and all shunt capacitance are equal and all series inductances are equal.

\section{TEST TRANSFORMER AND CALCULATION OF WINDING PARAMETERS}

\subsection{Test Transformer description}

To determine the transient's voltage distribution in the transformer windings, it is necessary to calculate the parameters of the winding i.e. inductance and capacitance. The study has been done on $100 \mathrm{KVA}$ single phase transformer having continuous disk type H.V. winding. The transformer data is given in Table 1 . 
Table 1: Test Transformer data

\begin{tabular}{|l|l|}
\hline Rating & $100 \mathrm{kVA}$ \\
\hline H.V. voltage & $11 \mathrm{kV}$ \\
\hline L.V. voltage & $433 \mathrm{~V}$ \\
\hline Frequency & $50 \mathrm{~Hz}$ \\
\hline $\begin{array}{l}\text { Insulation between core and } \\
\text { L.V. winding }\end{array}$ & Bablised Paper \\
\hline $\begin{array}{l}\text { Insulation over conductor } \\
\text { Insulation over layer }\end{array}$ & Paper \\
\hline $\begin{array}{l}\text { Insulation over L.V. and H.V. } \\
\text { winding }\end{array}$ & Bablised paper \\
\hline
\end{tabular}

Table 2 and 3 present core and windings data for the Test Transformer.

Table 2: Transformer Core data

\begin{tabular}{|l|l|}
\hline Diameter of core & $375 \mathrm{~mm}$ \\
\hline Width of window & $375 \mathrm{~mm}$ \\
\hline Height of window & $1335 \mathrm{~mm}$ \\
\hline CRGO lamination & $.33 \mathrm{~mm}$ \\
\hline $\begin{array}{l}\text { Distance between center of } \\
\text { adjacent limb }\end{array}$ & $685 \mathrm{~mm}$ \\
\hline
\end{tabular}

Table 3: Transformer Winding data

\begin{tabular}{|l|l|l|}
\hline Winding & L.V. & H.V. \\
\hline Type of winding & Helical & Disc \\
\hline Current density & $2.75 \mathrm{~A} / \mathrm{mm} 2$ & $2.92 \mathrm{~A} / \mathrm{mm} 2$ \\
\hline $\begin{array}{l}\text { Cross area of } \\
\text { conductor }\end{array}$ & $55 \mathrm{~mm} 2$ & $8.637 \mathrm{~mm} 2$ \\
\hline Number of disc & - & 10 \\
\hline Inside diameter & $405 \mathrm{~mm}$ & $571 \mathrm{~mm}$ \\
\hline
\end{tabular}

\begin{tabular}{|l|l|l|}
\hline $\begin{array}{l}\text { Outside } \\
\text { diameter }\end{array}$ & $507 \mathrm{~mm}$ & $649 \mathrm{~mm}$ \\
\hline $\begin{array}{l}\text { Mean length of } \\
\text { turn }\end{array}$ & $1432 \mathrm{~mm}$ & $1916 \mathrm{~mm}$ \\
\hline
\end{tabular}

\subsection{Determination of the transformer winding} parameters

\section{Capacitance calculation:}

Disc to disc capacitance for the winding have been calculated from the principle of electrostatic energy conservation [3].

Net series capacitance is given as:

$$
\mathrm{Cs}=\frac{\varepsilon_{0} \pi D}{N}\left[\frac{(n-1)}{n^{2}} \frac{\varepsilon_{\mathrm{t}\left(\mathrm{h}+2 \varepsilon_{\mathrm{E}}\right)}}{2 \varepsilon_{\mathrm{t}}}+\frac{4(N-1)}{\mathrm{aN}}\left(\frac{y+\varepsilon_{d}}{\frac{2 \varepsilon_{\mathrm{F}}}{\varepsilon_{\mathrm{t}}}+\frac{\varepsilon_{d}}{\varepsilon_{d}}}\right)\right]
$$

Where, $\quad \mathrm{D}=$ mean winding diameter

$\mathrm{N}=$ number of disc in the transformer

$\mathrm{n}=$ number of turn per disc

$\mathrm{h}=$ width of copper strip conductor

$\delta_{\mathbb{d}}=$ inter -disc space

$\delta_{t}=$ thickness of insulation

Disc to ground capacitance for winding have been calculated assuming that the coil, core leg and the metal tank form cylindrical electrode system.

Net shunt capacitance is given as: $C_{g=} \frac{2 \pi \varepsilon_{0}}{\ln \frac{b i d}{a r r}} \varepsilon_{t} l$

Where, $\mathrm{a}=$ Radius of core

$\mathrm{b}=$ Inner radius of L.V. winding

$\mathrm{c}=$ Outer radius of H.V. winding

$\mathrm{d}=$ Inner radius of H.V. winding

$l=$ Axial length of the H.V. winding

Inductance calculation [4]:

We have,

$\mathrm{L}=.001 \mathrm{aN}^{2} P_{0}$

If $\frac{c}{2 \alpha}<.2$, then

$P_{0}{ }^{\prime}=4 \pi\left[\frac{1}{2}\left(1+\frac{1}{6}\left(\frac{c}{2 a}\right)^{2}\right) \ln \frac{g}{\left(\frac{c}{2 a}\right)^{2}}-.8434+.2041\left(\frac{c}{2 a}\right)^{2}\right]$

\section{TRANSFORMER WINDING RESPONSE TO IMPULSE VOLTAGES}

When analyzing the impulse voltage distribution in the transformer winding a capacitive network is considered. In other words, the presence of series capacitances between 
winding sections causes the transformer to respond to abrupt impulses as a network of capacitances for all frequencies above its lower natural frequencies of oscillations.

$C_{g}$ And $C_{g}$ are the total ground capacitance and series capacitance of the transformer winding respectively. The ratio $\sqrt{C_{g} / C_{g}}$ has been denoted by the distribution constant $\alpha$.

To improve the transients response and to reduce the disc to disc voltage gradient the value of $\alpha$ is as small as possible. One way to reduce the value of $\alpha$ is to increase the value of $C_{g}$ which can be achieve by interleaving and inter-shielding [5].

\subsection{Simulation Result}

The behavioral response of the high voltage winding of the transformer have been analyzed using EMTP by simulating the circuit shown in Fig-1. An impulse voltage source having peak voltage 40 volt is apply on the excitation terminal and the voltage at various node is measured. The node voltage at $2^{\text {nd }}$ , $3^{\text {rd }}$ and last node is shown in below with isolated neutral. fig 2 , fig-3 and fig-4 show the node voltages when $\alpha$ is $10,3.5$ and 1 respectively.
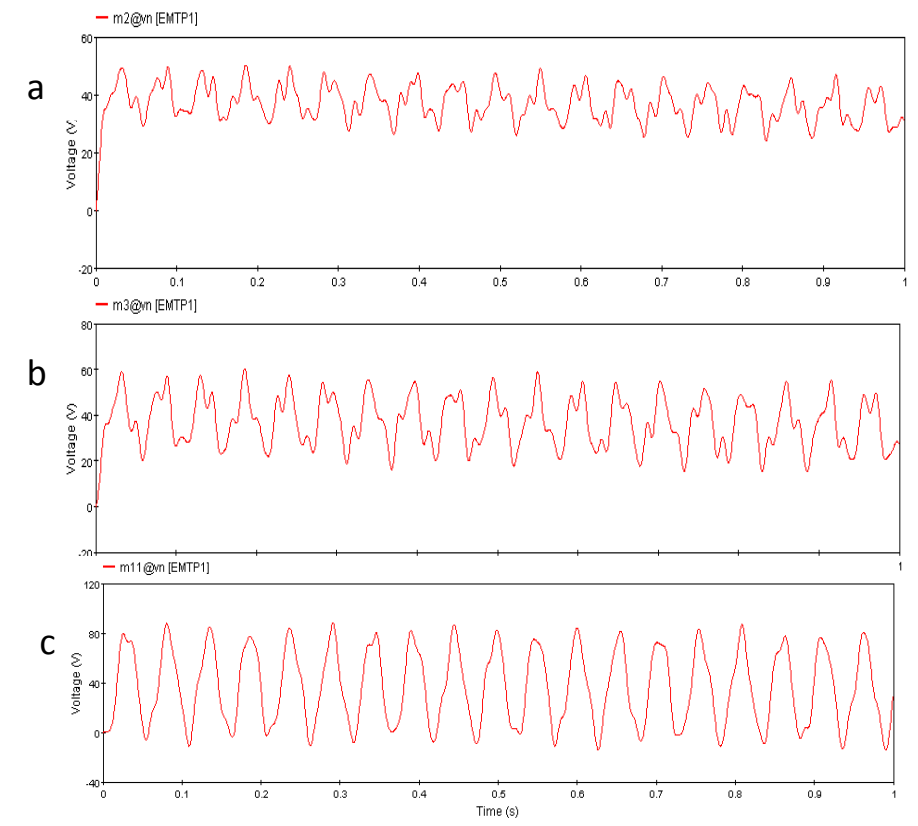

Fig2 : node voltage when $\alpha=10$ at a- $2^{\text {nd }}$ node $b-3^{\text {rd }}$ node $c-$ last node
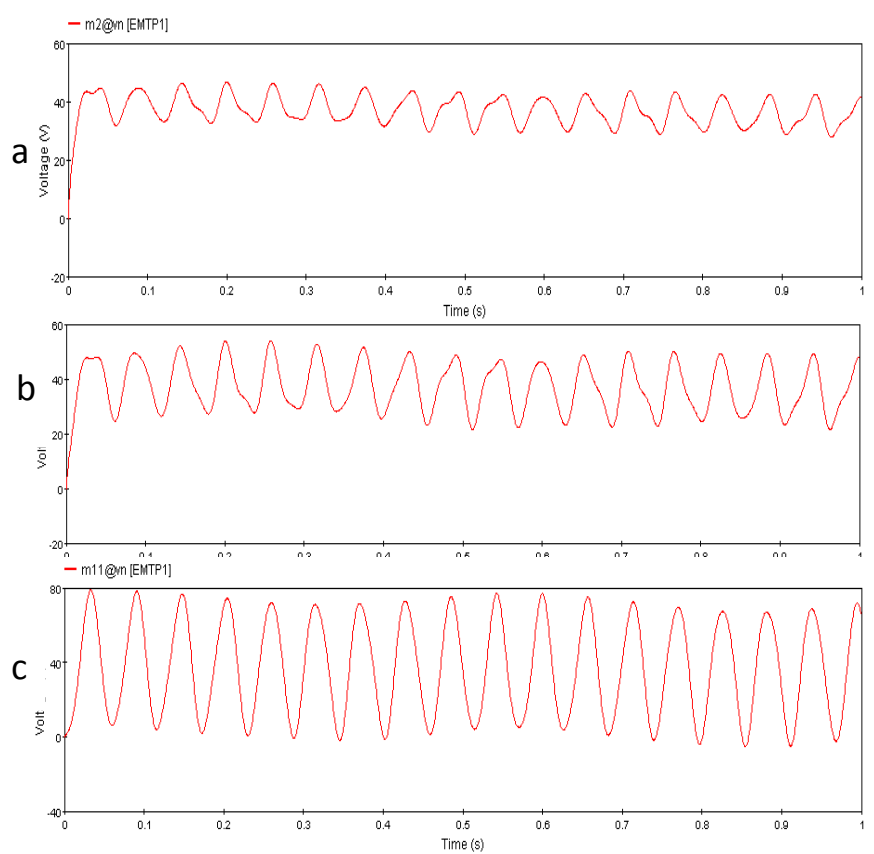

Fig3: node voltage when $\alpha=3.5$ at a. $2^{\text {nd }}$ node $b .3^{\text {rd }}$ node c. last node

a
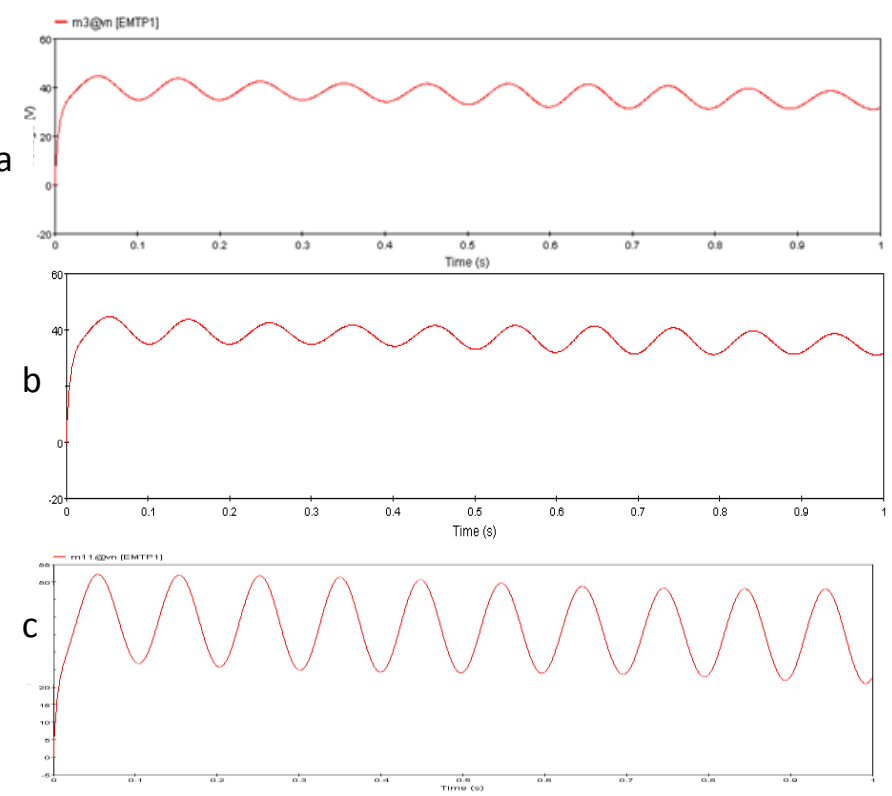

Fig4: node voltage when $\alpha=1$ at a. $2^{\text {nd }}$ node b. $3^{\text {rd }}$ node c. last node 


\subsection{Experimental results}

The transient response of the transformer winding is investigated using experimental set up as shown in Fig 5

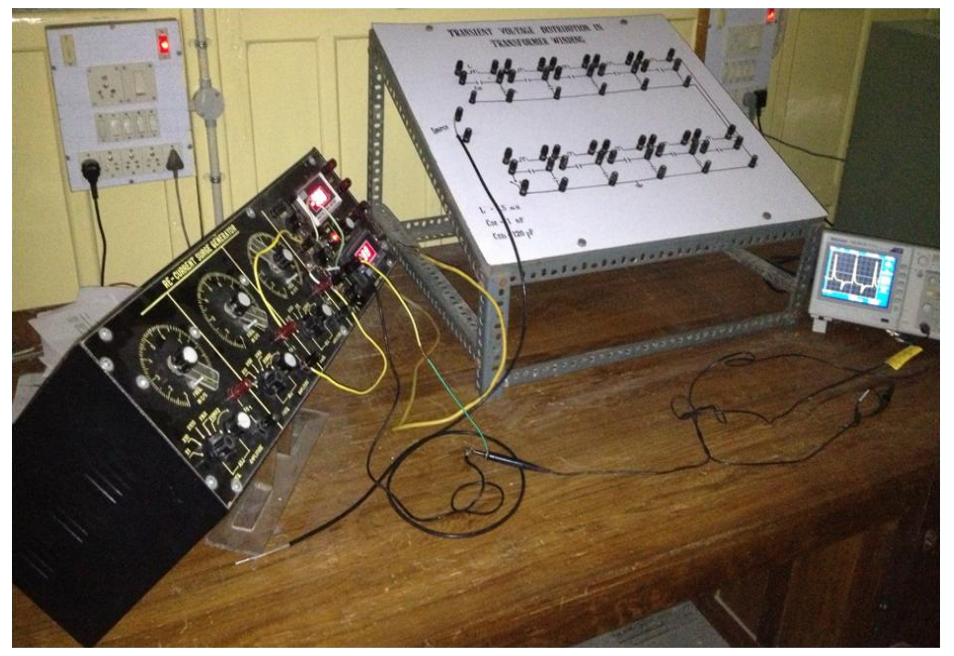

Fig 5 : Experiment set-up

In the experiment the same impulse voltage as in simulation was injected to the transformer winding model using the recurrent surge generator and the voltage at various node is observed using CRO.

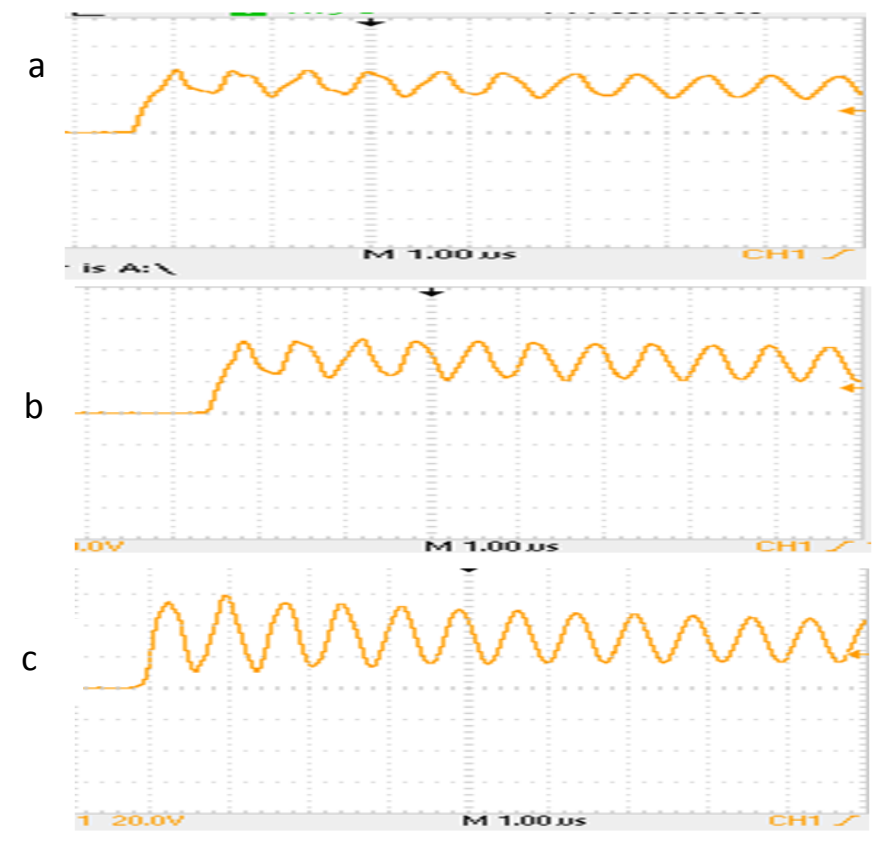

Fig 6: node voltage when $\alpha=10$ at a. $2^{\text {nd }}$ node b. $3^{\text {rd }}$ node c. last node

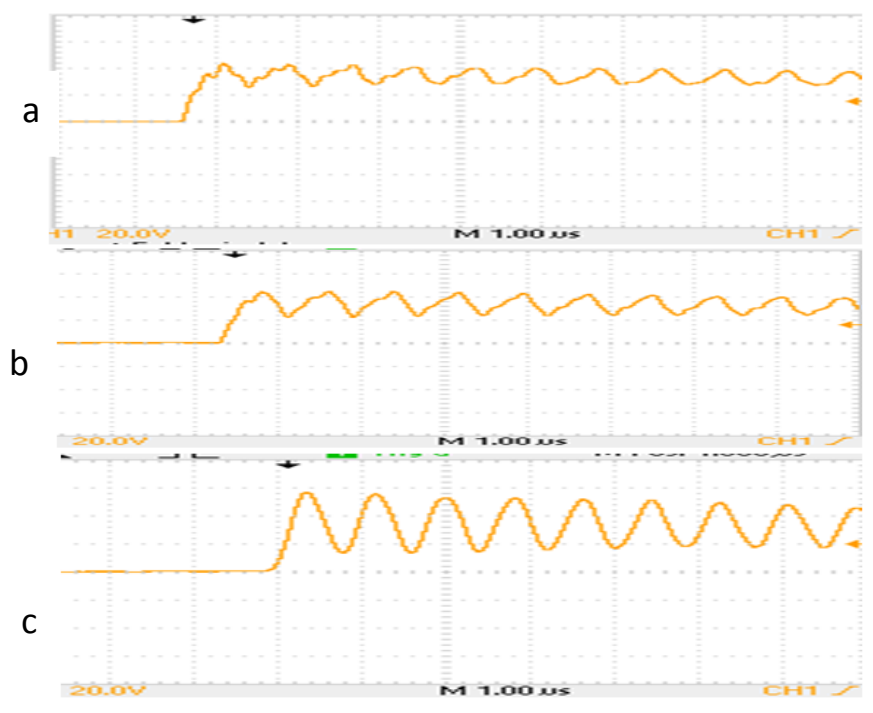

Fig 7: node voltage when $\alpha=3.5$ at a. $2^{\text {nd }}$ node b. $3^{\text {rd }}$ node c. last node

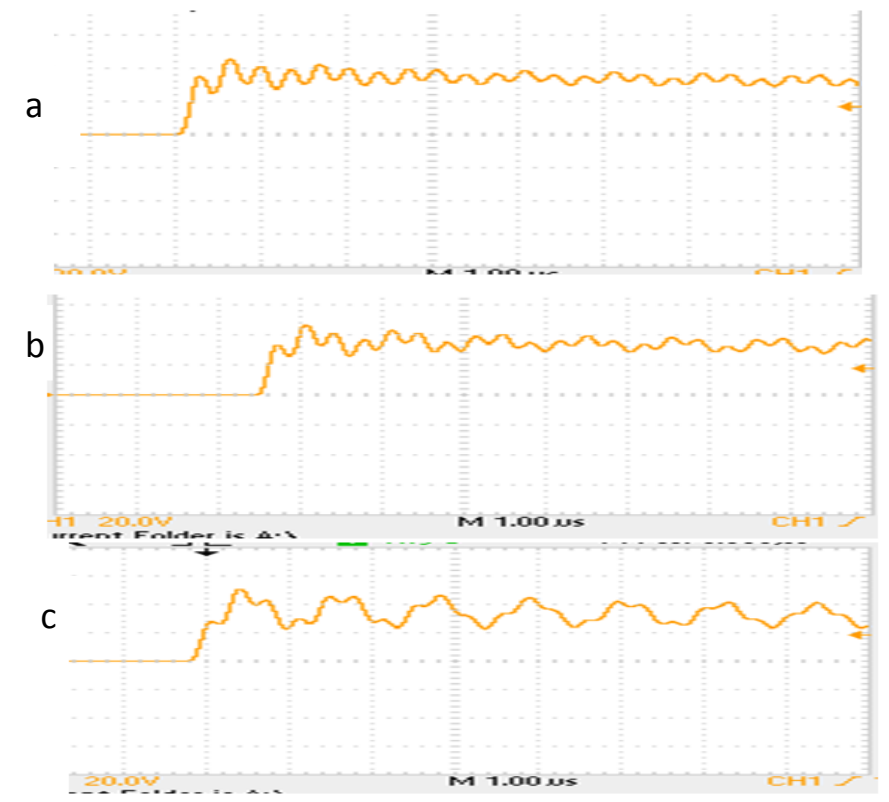

Fig 8 : node voltage when $\alpha=1$ at a. $2^{\text {nd }}$ node b. $3^{\text {rd }}$ node c. last node

\section{CONCLUSIONS}

The result obtained from the EMTP simulation closely agrees with the experimental results. Impulse response of transformer winding is oscillatory. If the oscillation frequency equals the transformer natural frequency, then oscillatory transients response can trigger internal resonance. Voltage at different node shows that oscillation is reduced as the value of $\alpha$ is decreases. 
Results also indicate that voltage distribution in the transformer is highly non uniform with larger value of $\alpha$ as compare to when value of $\alpha$ is low.

\section{ACKNOWLEDGEMENTS}

The authors wish to thank Prof. S.P. Singh, the Head of Electrical Engineering, Indian Institute of technology (BHU) Varanasi for providing necessary computational and laboratory facility for successful completion of this work.

\section{REFERENCES:}

[1]. Y. Shibuya, S. Fujita and T. Shimomura "Effects of very fast transients overvoltage on transformer" IEE, volume 146 No.4 july 1999.

[2]. Gao Youhua ,Yuan Hong, Wang Erazi, and Cao Yundong "Calculation Of Very Fast Transients Over-Voltage And Its Distribution In Transformer Winding In $110 \mathrm{kV}$ GIS".proceedingof international conference on electrical machines and systems 2007 ,oct 8 11 Seoul Korea

[3] Robert M. Delvecchio, Bertrand poulin, Dilip Kumar M. shah, Rajendra Ahuja "Transformer Design principle Chapter 12.

[4].Grover, F.W., "Inductance Calculations: Working Formulas and Tables", Dover Publication, Inc-1962.

[5] Mehdi Bagheri, Mehdi Vakilian, Arsalan Hekmati, Rouhollah Heidarzadeh "Influence of Electrostatic Shielding of Disc Winding on Increasing the Series Capacitance in Transformer" Power Tech, 2007 IEEE Lausanne.

\section{BIOGRAPHIES:}

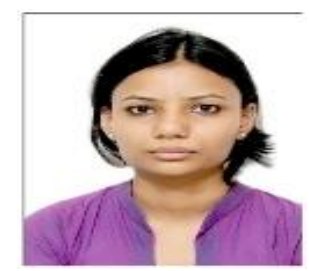

Obtained the Under Graduate degree from B.B.D. National Institute of Technology \& Management, Lucknow. Presently doing Post Graduation from Indian Institute of Technology, BHU, Varanasi

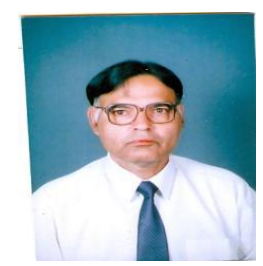

Obtained the Under Graduate and Masters degree from University College of Engg. Burla, Sambalpur University, Odissa, and $\mathrm{Ph} . D$. from Institute of Technology, BHU, Varanasi. Presently, working as Professor in IIT (BHU) Varanasi. 